مجلة علوم الرافدين، المجلد 27، العدد 4/ عدد خاص بالمؤتمر العلمي الثالث لعلوم الحباة، ص223-231، 2018

تأثيرات الجرع الزائدة من الباراسيتامول في بعض المعايير المناعية اللانوعية

\author{
روجان غانم محمد العلاف

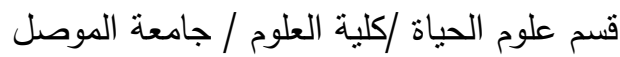 \\ (أستلم 2018/10/ 2018/11/
}

\begin{abstract}
الملخص
تضمن البحث دراسة متابعة تأثثر الاستخدام المفرط للباراسيتامول في بعض المعايير المناعية اللانوعية، حيث

شملت الدراسة تقدير الاعداد الكلية للخلايا البيضاء وحساب الاعداد المطلقة للخلايا العِدلة واللمفاوية والوحيدة النواة فضلا عن

تقدير الفعالية البلعمية وشملت الدراسة جمع (30) نموذج دم من أفراد يستخدمون الباراسيتامول بشكل مفرط وبإعمار تراوحت وهن بين(20-40) سنة ومن كلا الجنسين، واستخدمت عينات دم من أشخاص متبرعين لايستخدمون عقار الباراسيتامول كعينة سيطرة،

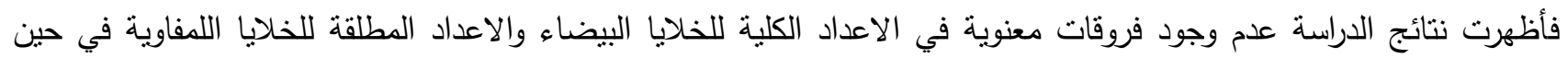
لوحظ وجود ارتفاع معنوي في الاعداد المطلقة للخلايا العدلة والخلايا وحيدة النواة مقارنة بعينة السيطرة، أما فيما يتعلق بالفعالية البلعمية فقد أظهرت النتائج وجود انخفاض معنوي في الفعالية البلعمية لدى الأشخاص الذين يستخدمون عقار الباراسيتامول بشكل مفرط مقارنة بعينة السيطرة.
\end{abstract}

الكلمات الدالة : البار اسيتامول، الاستجابة المناعية اللا نو عية،NBT.

\title{
Effects of Paracetamol in Non-Specific Immunological Parameters
}

\author{
Rojan G.M. AL-Allaff \\ Department of Biology /College of Sciences/University of Mosul
}

\begin{abstract}
Our study includes follow up the effect of excessive dose of paracetamol in some individuals on non- specific immunological parameters, the study estimates total white blood cell count and calculates the absolute number of neutrophils, lymphocytes and monocytes in blood, and estimation of the effectiveness of phagocytic cells of neutrophils. The study included the collection of (30) blood samples from individuals used paracetamol with excessive dose with age range between (20-40) years of both sexes, blood samples individuals donors do not use paracetamol as control samples were used as well. The results showed no significant differences in number of total white blood cell count and number of lymphocytes for individuals with excessive dose of paracetamol compared with control, on another hand the results showed a significant increase in number of neutrophils and monocytes compared with control, concerning the phagocytic activity, the results showed a significant reduction in phagocytic activity in individuals with excessive dose of paracetamol compared with control.
\end{abstract}

Keywords: Paracetamol, Non-specific immune response, NBT. 


\section{المقدمة}

أكتثـــ الباراسـيتامول فـي عـام 1878 مـن قبـل العـالم مــورس، وعـرض للاسـتخدام الطبـي فـي عـام 1883 بسـبب ســوء تفسـير ســلامته، كمـا بقـي اسـتعماله محسدودا حتهى عـام 1955، ويصـنف الباراسـيتامول كـأكثر المسـكنات

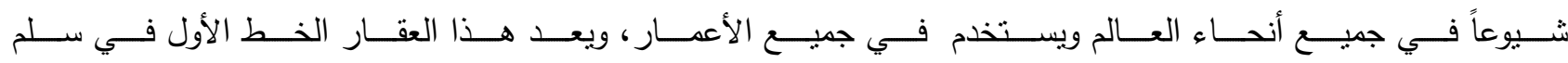

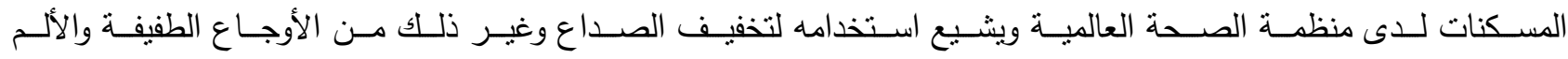

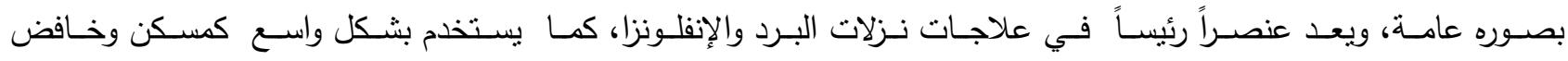

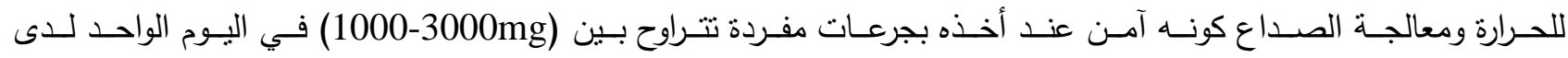

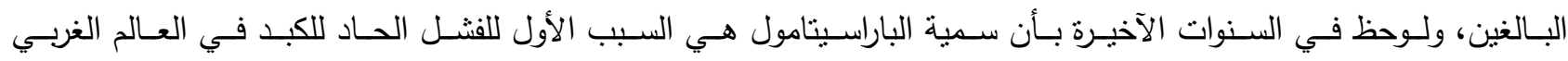

.(Hawkins et al., 2007)

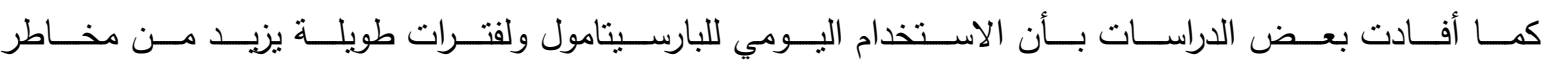

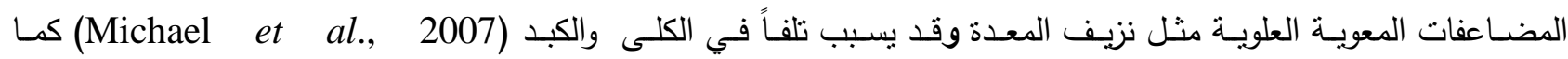
اكتثفت الثأثثرات الجينية للباراسيتامول في الفئران والجرذان (Hongslo et al., 1993).

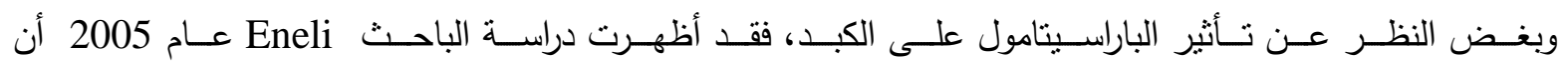

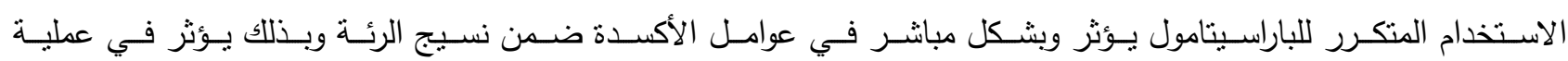
التتفس بالإضافة الى علاقته بالتهابات الأنف والربو لدى البالغين (Eneli et al., 2005).

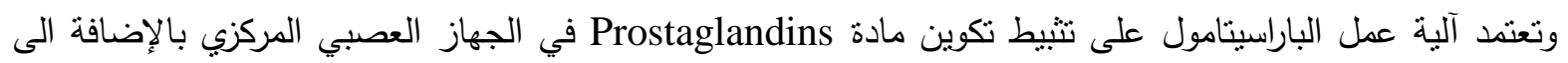
تأثثره في خفض الحرارة بوساطة التأثثر في مركز تتظيم الحرارة بغدة الوطاء (تحت المهاد) Hypothalamus فيعمل على زيادة

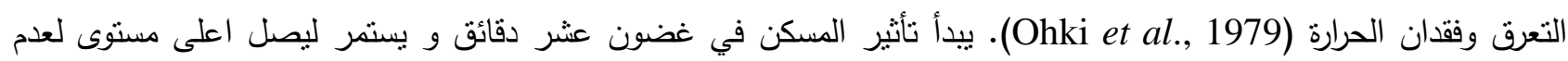

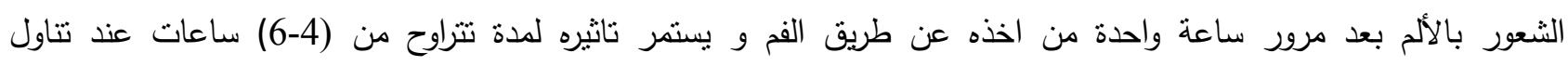

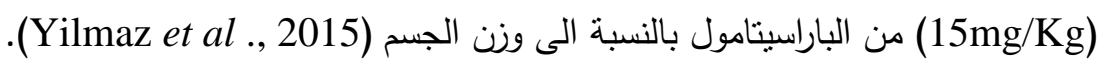

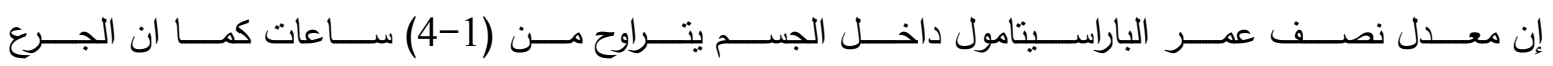

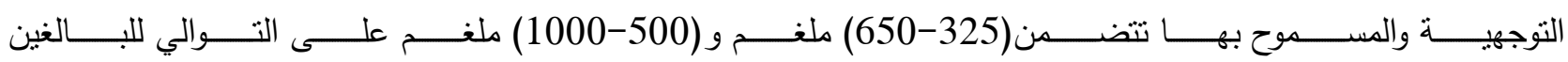

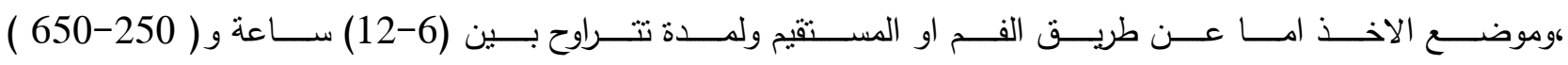

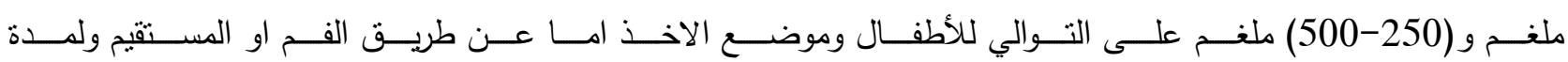

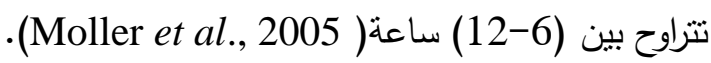
ويعود التسـم بعقـار الباراسـيتمول السى الإفـراط في اسـتخدامه (Woolley and Woolley, 2017) حيث

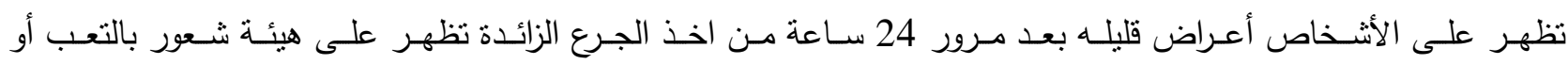

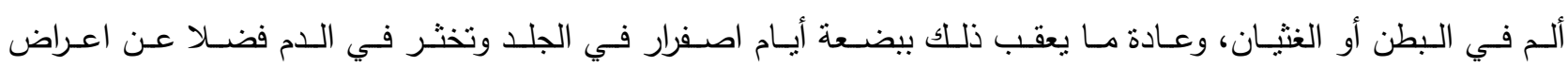
أخرى كالفثل الكلوي والتهاب البنكرياس وانخفاض السكر في الدم (Yoon et al., 2016).

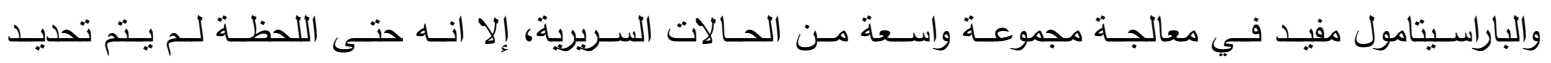

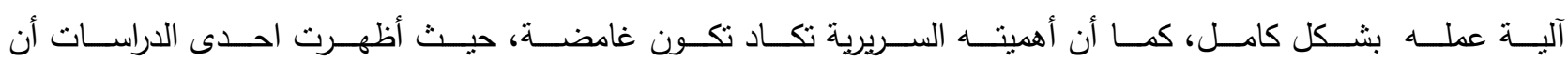

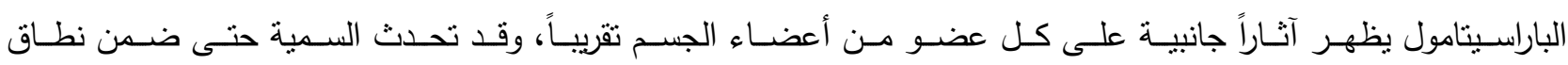

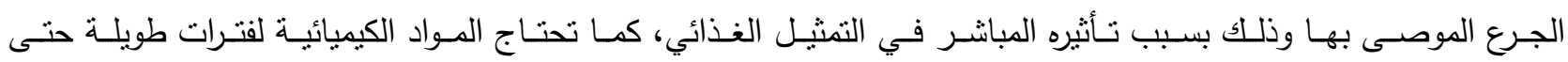

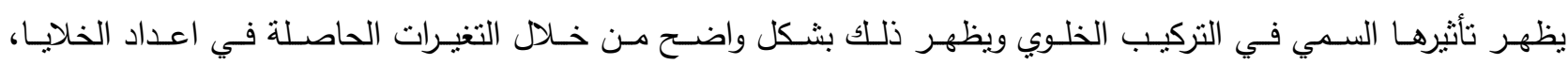




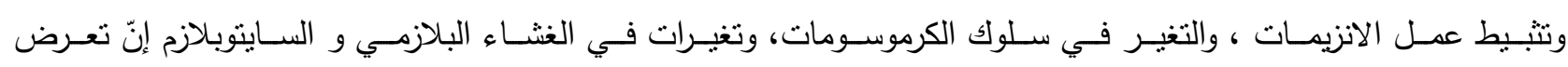

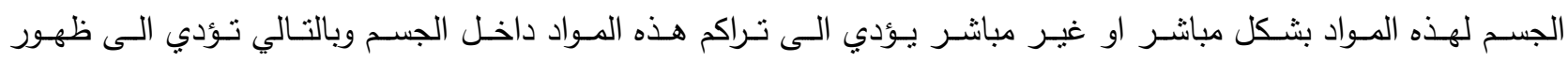
العديد من الامراض الوراثية ومن اهمها السرطان (Nabal et al . 2012).

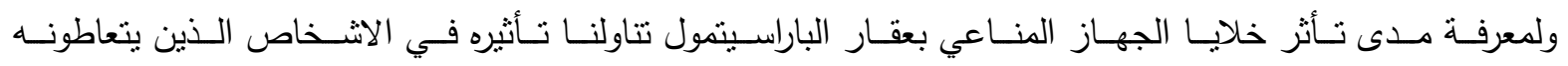

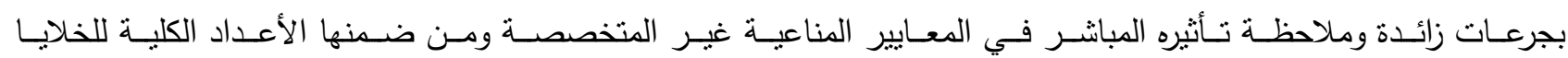

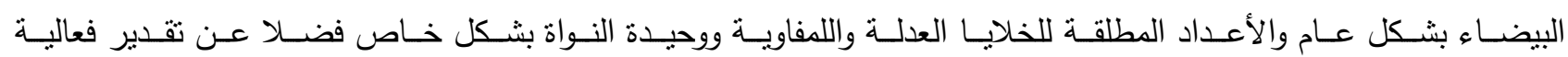
الخلايا البلعمية لدى اولئك الأشخاص. لئ.

\section{المواد وطرائق العمل}

العينات:

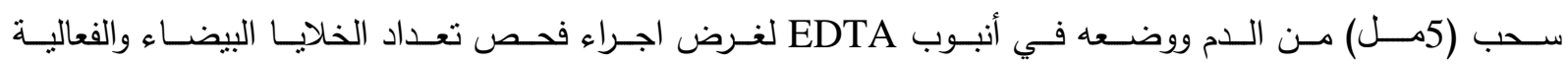

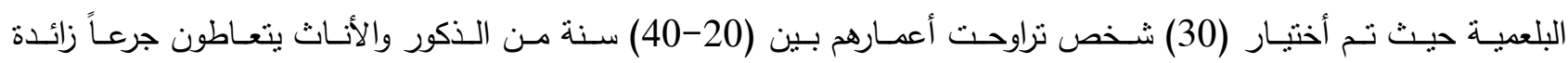

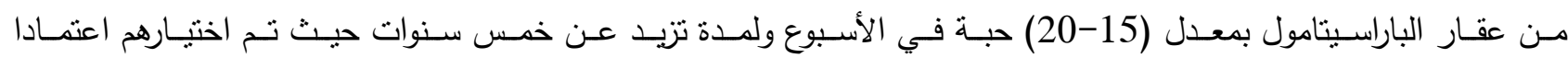

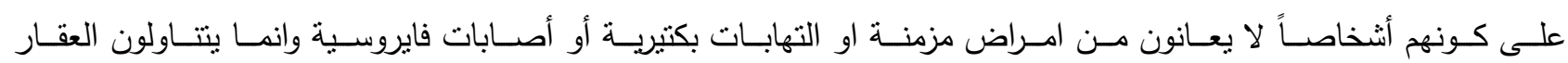

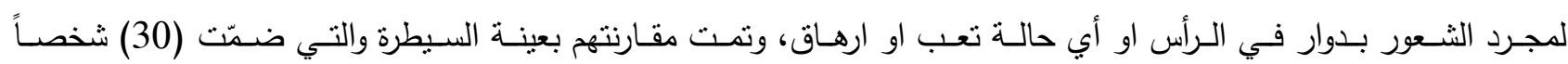
لا يتعاطون المسكنات ومن ضمنها الباراسيتامول بصورة مفرطة. تعداد خلايا الام البيضاء :-

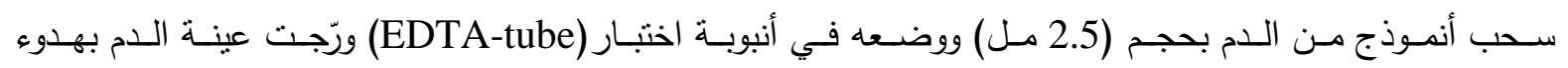
لكي بمتزج الدم بصورة جيدة مادة (EDTA).

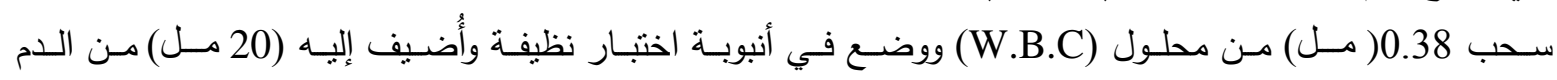
ورّج بصورة جيدة لمدة (3-2) دقائق.

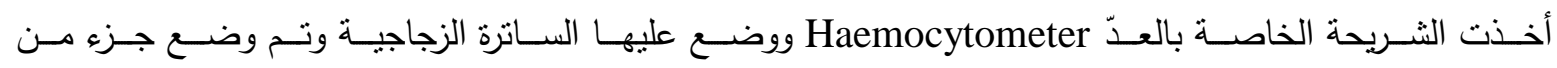

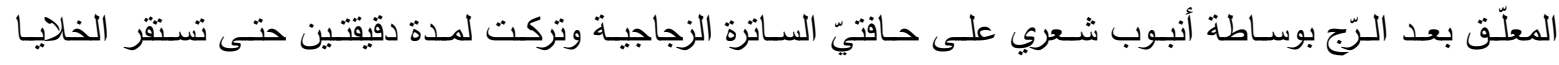

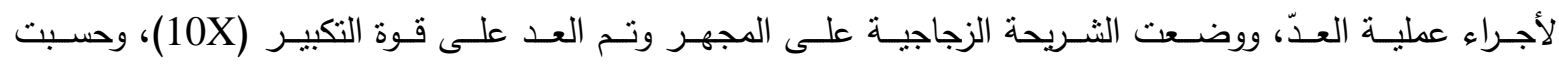
أعداد الخلايا البيضاء كما في المعادلة الاتية:

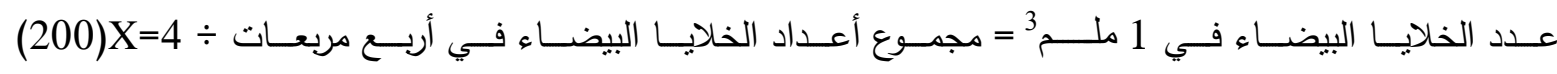
(Lewis and Bain, 2001) العد التفريقي لخلايا الام البيضاء :-

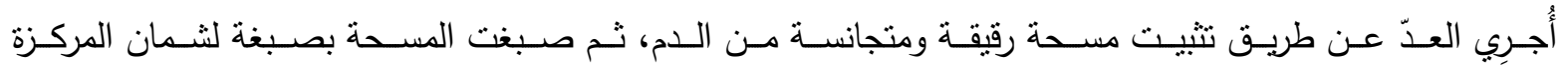

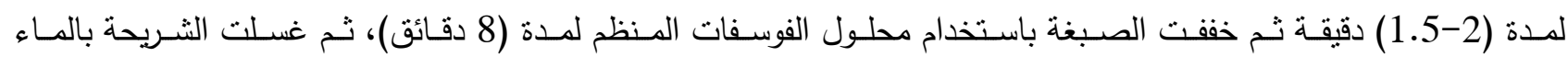
الاعتبـادي وتركـت لتجـف، وتـم فــص (100 خليـة بيضـاء) لكـل عينـة (Mckenzie,1996). وحسـبت الاعـداد المطلقـة للخلايا البيضاء

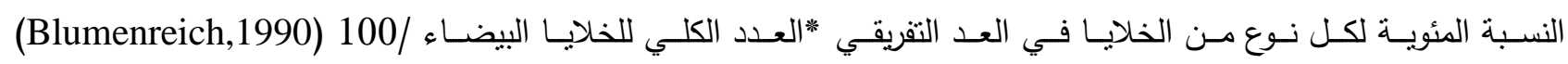
.(Allaff and AL-Shahery,2012) 
اختبار الفعالية البلعمية:-

نقـل( 50 مـايكرولتر) مـن محــول صـبغة NBT المجهـزة مـن قبـل شـركة SIGMA-ALDRICH الصـينية الـى انبوب زجاجي.

اضــف (50 مـايكرولتر) مـن الــم المــزوج مـع مـادة EDTA الـى محلـول الصـبغة مـع مراعـاة مـزج العينـات بشـكل خفيف.

اجريت عملية تحضين العينات عند (37) درجة مئوية ولمدة (30) دقيقة. اجراء عملية مزج العينة بشكل خفيف كل عشرة دقائق ضمن فترة التحضين.

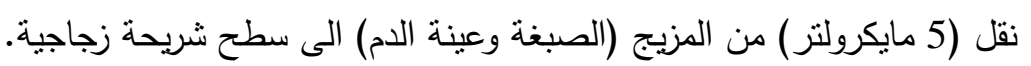

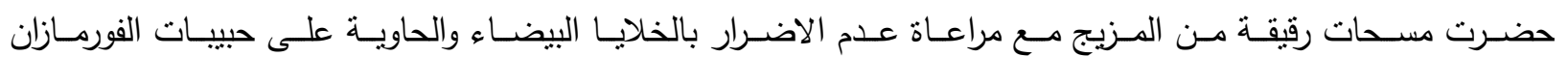
المختزلة والتي تكون هشة وقابلة للتحطم. عرضت جميع المسحات للتجفيف بواسطة الهواء

صبغت جميع المسحات بصبغة ليشمان Leishman stain. نم عمل ثلاثة مكررات لكل عينة وذلك لتقليل نسبة الخطأ التجريبي.

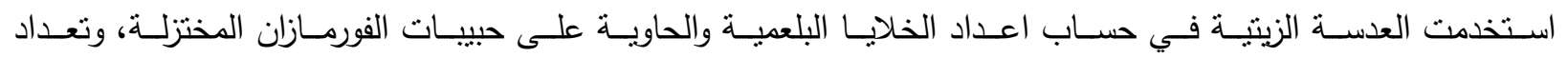
(100) خلية لكل مسحة دم، ونم اعتماد النتيجة الموجبة بظهور حبيبات الفورمازان السوداء داخل الخلية البلعمية. النسبة المئوية = عدد البلاعم المختزلة لصبغة NBT /عدد البلاعم الكلي × 100 (Simmons and statland, 1997). التحليل الإحصائي: -

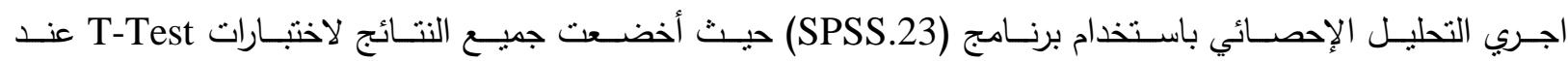
مستوى معين (P<0.05).

\section{النتائج والمناقشة}

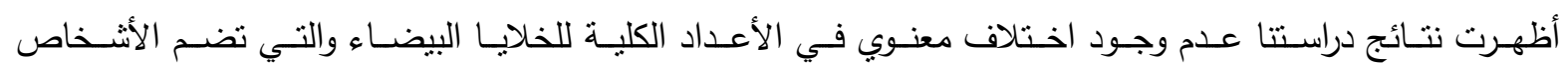

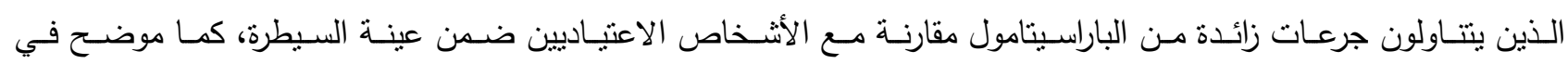

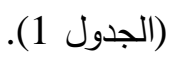

الجـدول 1: مقارنـة الأعداد الكليـة لخلايـا الــدم البيضـاء بـين الأثـخاص الـذين يتــاولون جرعـات زائـدة مـن الباراسيتامول

\begin{tabular}{|c|c|c|c|c|}
\hline & & & \multicolumn{2}{|c|}{ وعينة السيطرة } \\
\hline Sig & $\begin{array}{c}\text { Extrem values } \\
\text { cell } / \mathbf{m m}^{3}\end{array}$ & $\begin{array}{l}\text { Mean } \pm \text { S.D. } \\
\text { cell } / \mathbf{m m}^{3}\end{array}$ & $\begin{array}{c}\text { No.of } \\
\text { Subject }\end{array}$ & Groups \\
\hline \multirow[t]{2}{*}{0.275} & $4500-9400$ & $7725 \pm 2077$ & 30 & Samples \\
\hline & $4000-9500$ & $7171 \pm 1804$ & 30 & Control \\
\hline
\end{tabular}

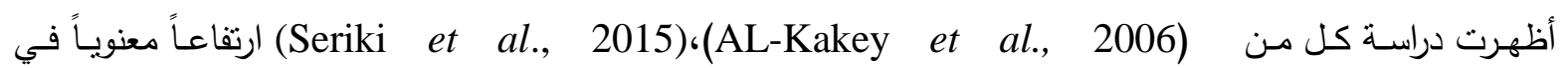

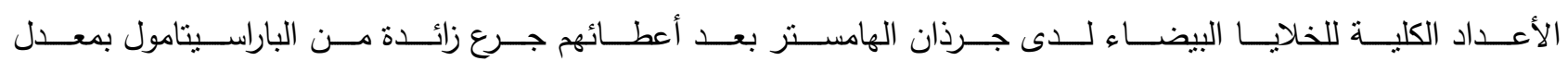
(300mg/day)

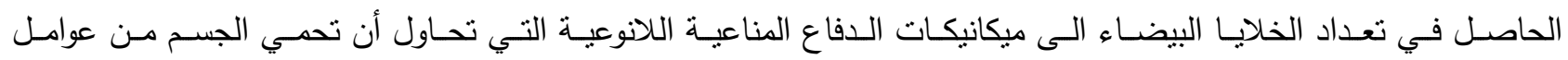




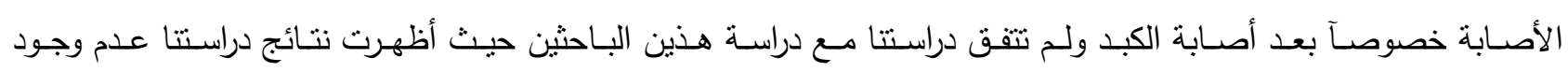

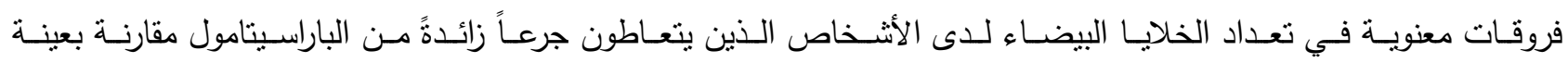

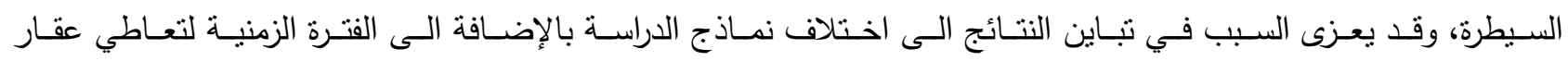

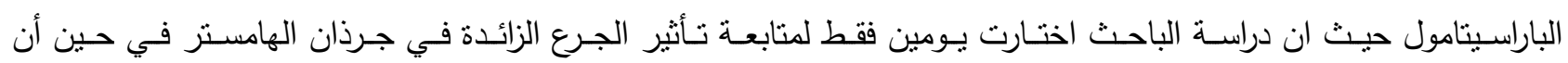

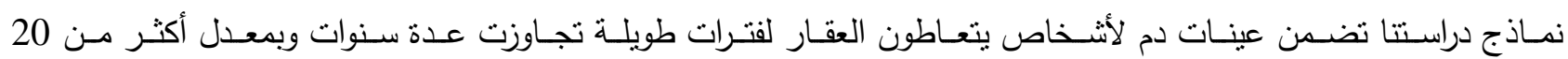
حبة في الأسبوع الواحد.

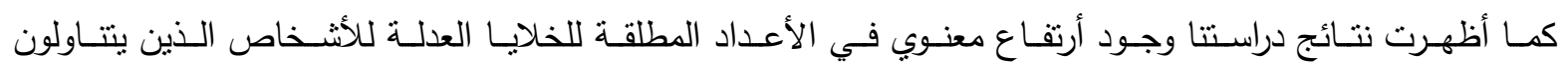

جرعات زائدة من الباراسيتامول مقارنة مع الأشخاص الأعتياديين ضمن عينة السيطرة، وكما موضح في في (الجدول 2)

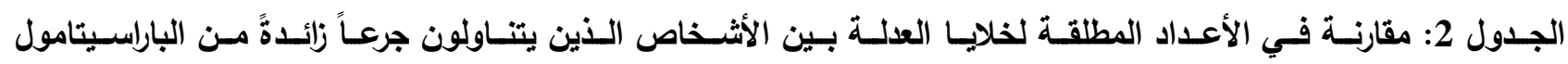
مقارنة بعينة السبطرة

\begin{tabular}{|c|c|c|c|c|}
\hline Sig. & $\begin{array}{c}\text { Extrem values } \\
\text { cell//mm }\end{array}$ & $\begin{array}{c}\text { Mean } \pm \text { S.D. } \\
\text { cell } / \mathbf{m m}^{3}\end{array}$ & $\begin{array}{c}\text { No.of } \\
\text { Subject }\end{array}$ & Groups \\
\hline \multirow[t]{2}{*}{$0.001 *$} & $2014-7257$ & $4412 \pm 1666$ & 30 & Samples \\
\hline & $1800-7250$ & $3583 \pm 295$ & 30 & Control \\
\hline
\end{tabular}

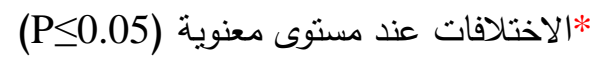

تضمنت دراستتا الحالية تقدير أعداد وفعالية الخلايا البلعمية لما لها من أهمية بالغة في دفاعات الجسم اللانوعية فضلا

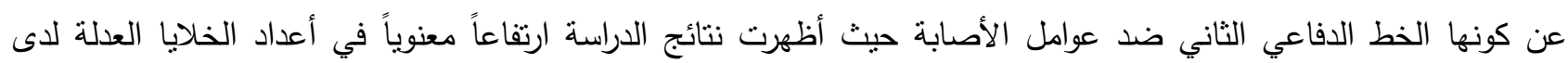

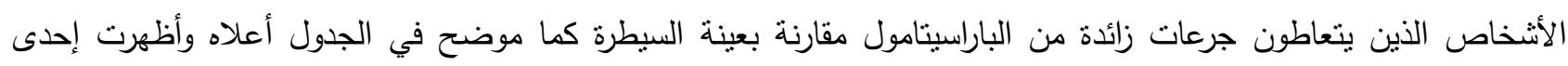

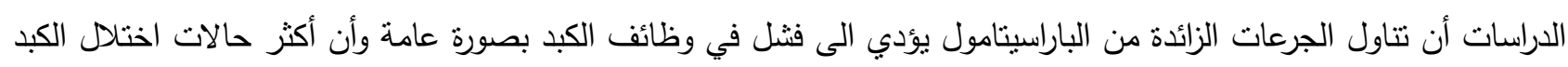

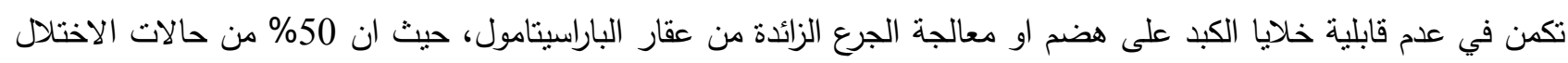

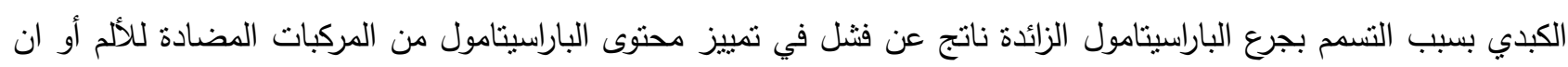

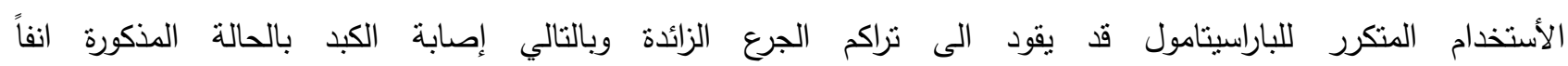
(Larson et al., 2005). وأظهرت دراسة Mitchell وآخرون عام 1973 التي تعاملت مع الحيوانات المختبرية أن أختلال الكبد قد يعود الى تكون مركبات وسطية فعالة تبدأ بإستنزاف الكلوتاثيون glutathione وإحداث تغييرات تساهمية في البروتينات

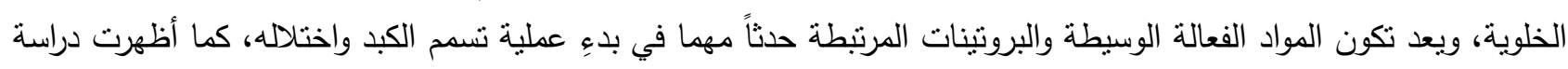
اخرى وجود تغيرات تساهمية في بروتينات المايتوكوندريا والتي تحث على حدوث اختلال وظيفي في عضيات المايتوكوندريا،

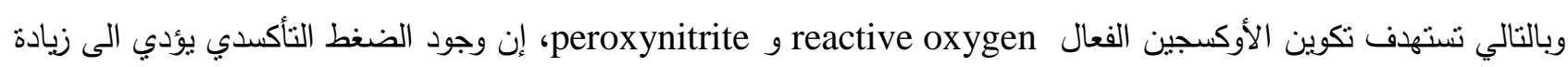
نفاذية أغثية المايتوكوندريا وبالتالي فقدان جزئيات الطاقة ATP بالإضافة الى ذلك فإن تحطيم عضيات المايتوكوندريا يحرر عدداً

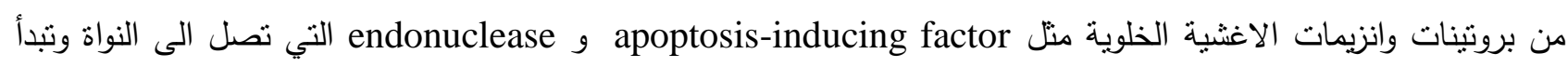
عملية تحلل DNA الخاص بالخلية الكبدية وقد لوحظت هذه الظاهرة بوجه خاص عند استخدام الجرع الزائدة من عقار الباراسيتامول كمضادات للألم (Jaeschke and Bajt, 2006). هذه العوامل مجتمعة نستهدف الاستجابة الالتهابية يتادول inflammatory response وأول نوع من خلايا الدم البيضاء التي تبدأ بالتجمع حول الخلايا الكبدية العليلة هي الخلايا العدلة neutrophils حيث تبدأ هذه الخلايا بتحفيز العديد من العوامل الخلوية الوسيطـة منل High mobility group box-1(HMGB1 وهو عبارة عن بروتين كروماتيني يُفرَز بواسطة الخلايا المتخرة (Scaffidi et al., 2002). إن البروتين HMGB1 له قدرة الارتباط مع مستقبل خاص على سطح خلايا Hupffer 
cells وتحفيز إنتاج السايتوكنيات الأولية والمحفزة للعملية الالتهابية وبالتالي تتشيط وتجميع الخلايا العدلة حول جيوب الخلايا الكبدية المتضررة (Tsung et al., 2005)، إن الهدف من تجمع الخلايا العدلة حول هذه الخلايا إزالة الخلايا المتضررة والميتة

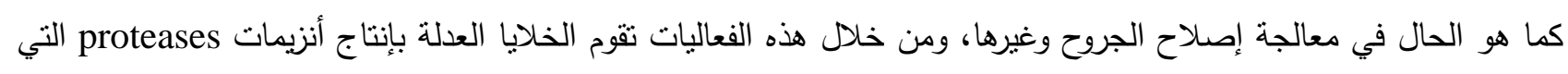

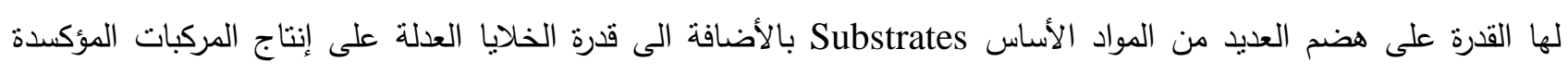

السامة منل Hydrogen peroxide, hypochlorous). إن الخلايا العدلة المنظمة عند موقع الخلل في الكبد لا تهاجم الخلايا الصحية بل تهاجم الخلايا الميتة والخلايا المجهدة

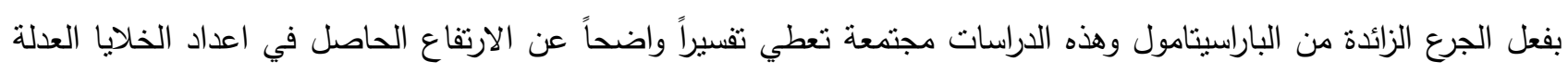

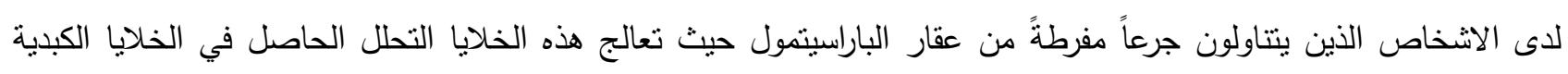
والسيطرة على العملية الالتهابية.

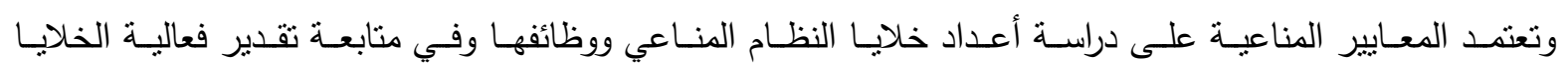

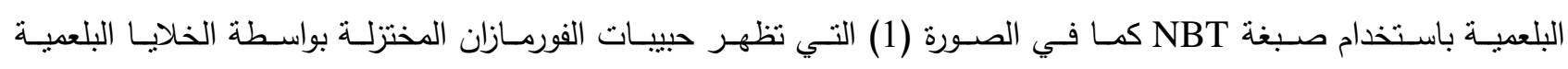

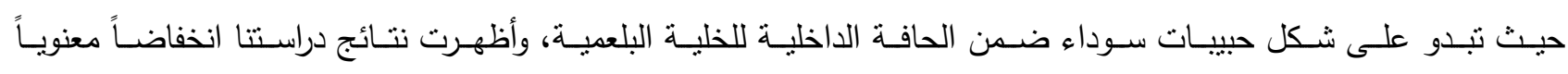

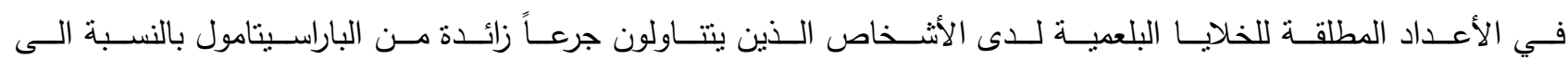
الأشخاص الأعنياديين ضمن عينة السيطرة، كما هو موضح في (الجدول 3).

حبيبات الفورمازان

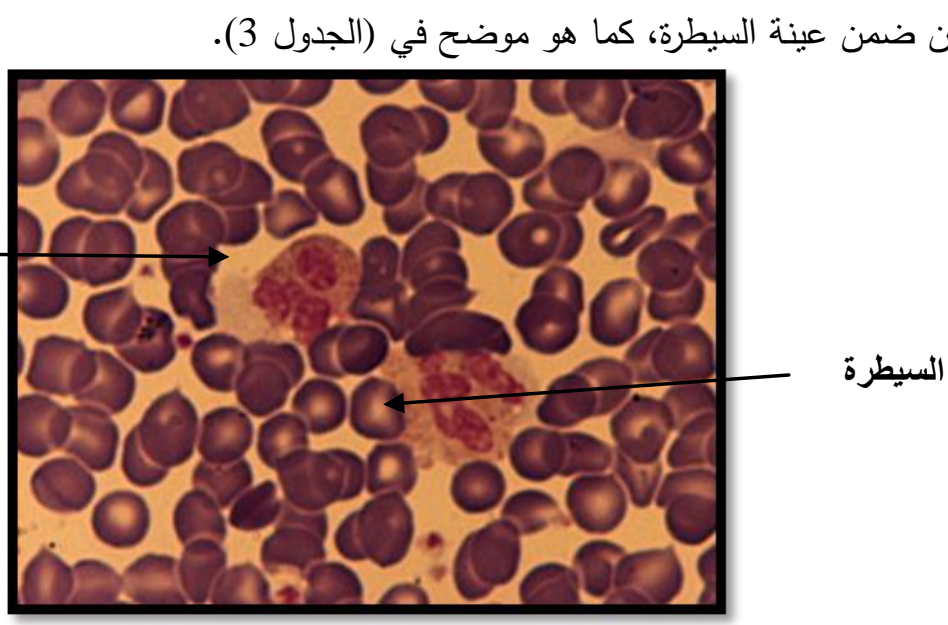

الصورة1: الخلية البلعمية الحاوية على حبيبات الفورمازان الداكنة مقارنة بالسيطرة (100X)

الجـدول 3: مقارنــة الأعـداد المطلقـة لخلايــا البلعميـة للأشـخاص الـذين يتـــاولون جرعـاً زائــدة مـن الباراسـيتامول بعينـة السيطرة

\begin{tabular}{|c|c|c|c|c|}
\hline Sig. & $\begin{array}{c}\text { Extrem values } \\
\text { cell/:mm } \mathbf{m m}^{3}\end{array}$ & $\begin{array}{c}\text { Mean } \pm \text { S.D. } \\
\text { cell/mm }\end{array}$ & $\begin{array}{c}\text { No. } \\
\text { of Subject }\end{array}$ & Groups \\
\hline \multirow[t]{2}{*}{$0.007^{*}$} & 894-1952 & $1245 \pm 391$ & 30 & Samples \\
\hline & $550-2700$ & $1449 \pm 77$ & 30 & Control \\
\hline
\end{tabular}

(P 1 (الاختلافات عند مستوى معنوية (*0.05)

اظهـرت نتـائج دراسـة الباحـث Olatosin وآخـرين عـام 2007 الـذي اسـتخدم الجـرذان المعاملـة بجـرع زائـدة مـن

الباراسيتمول انخفاضاً كبيراً في نركيز الهيموغلوبين في دم تلك الفئران (Olatosin et al.,2007).

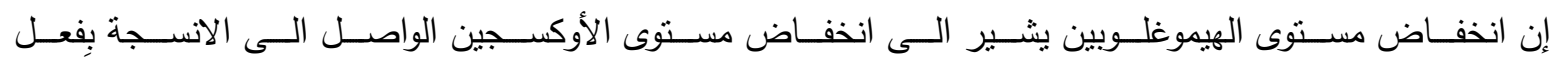

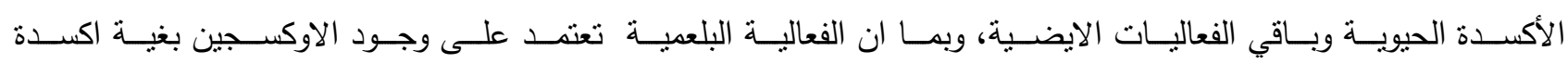


وتحطيم المستضــات الغريبـة التـي مسن المكـن ان تـدخل الجسـم بسـبب انزيمـات Protease وانـزيم lysozyme كمــا ان

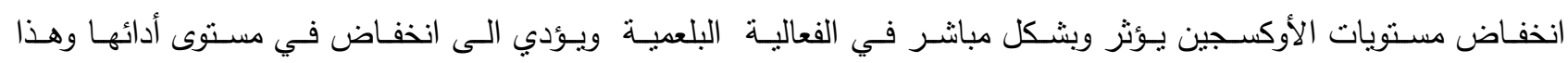

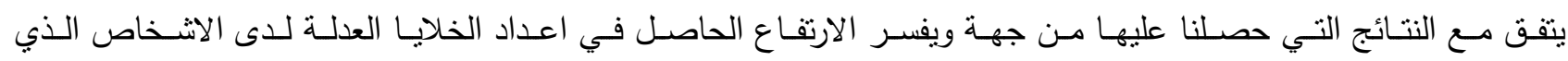

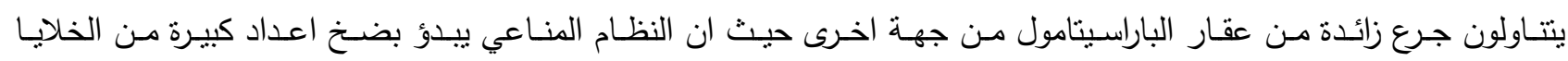

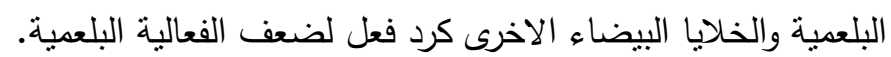

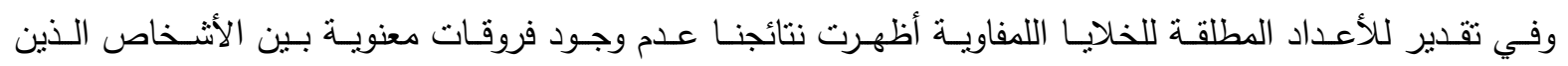

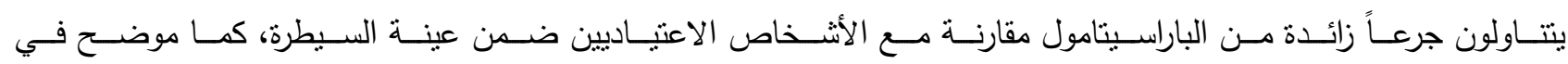

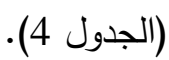

الجدول 4: مقارنـة فـي الأعداد المطلقـة لخلايـا اللمفاويـة بـين الأثـخاص الذين يتــاولون جرعـاً زائـدة مـن الباراسـيتامول

\begin{tabular}{|c|c|c|c|c|}
\hline & & & \multicolumn{2}{|c|}{ معاربه بعيبه السيطره • } \\
\hline Sig. & $\begin{array}{l}\text { Extrem values } \\
\text { cell } / \mathbf{m m}^{3}\end{array}$ & $\begin{array}{c}\text { Mean } \pm \text { S.D. } \\
\text { cell } / \mathrm{mm}^{3}\end{array}$ & $\begin{array}{c}\text { No. } \\
\text { of Subject }\end{array}$ & Groups \\
\hline \multirow[t]{2}{*}{0.586} & $1610-3936$ & $2486 \pm 615$ & 30 & Samples \\
\hline & $1090-4600$ & $2420 \pm 218$ & 30 & Control \\
\hline
\end{tabular}

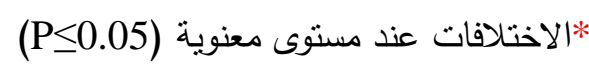

أظهرت دراسة الباحث (ELGarbulli and Bashashq, 2008) التي تتاول فيها تأثنرات الباراسيتامول في المكونات الجينية (genetic material) من خلال متابعة المؤشرات الانقسامية Mitotic index وسلوك الكرموسوم في اثثاء انقسام خلايا الدم البيضاء لاى الانسان، حيث اظهرت دراسته ان الباراسيتامول يزيد من معدل انقسام الخلية إذا كان تركيزه منخفضا منها فئه في

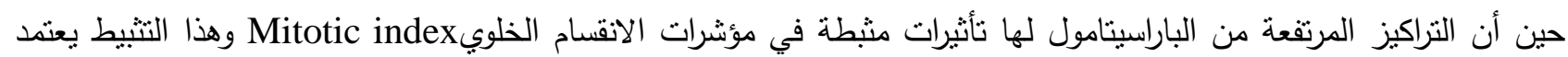

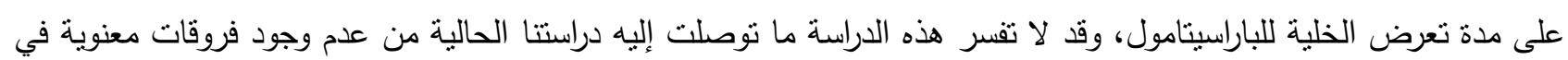
مستويات الخلايا اللمفاوية لدى الاثخاص الذين يتعاطون الباراسيتامول بجرع عالية لفترات طويلة مقارنة مع الاشخاص الاعتياديين، ولكنها تعطينا اثشارة واضحة في ان التراكيز العالية من الباراسيتمول تؤثز وبشكل مباشر في اعداد الخلايا اللمفاوية.

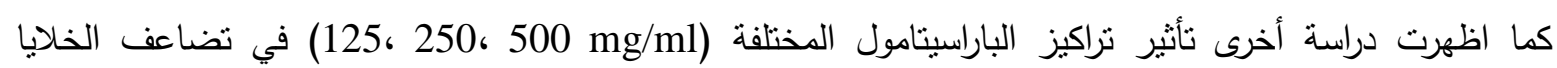
اللمفاوية حيث تحث هذه التراكيز على تقطيع جزئيات DNA الخاصة بالخلايا اللمفاوية وبالتالي تطور عملية القتل المبرمج، وهذه

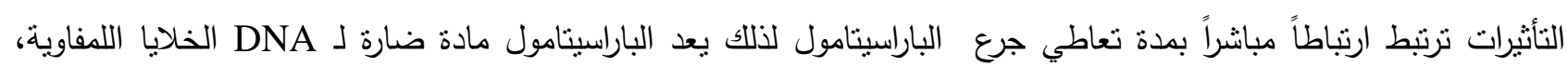
وبالتالي فهو ذو أضرار جانبية عالية اكثر من فائدته في تسكين الألم (Thura, 2014).

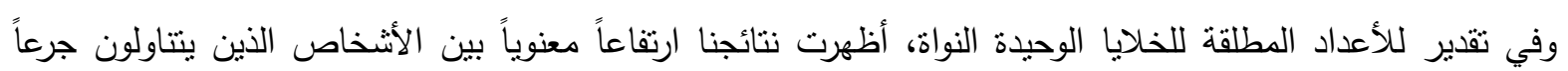
زائدة من الباراسيتامول بالنسبة الى الأشخاص الاعتياديين ضمن عينة السبطرة، كما موضح في (الجدول 5).

الجدول 5: مقارنة الأعداد المطلة للخلايا وحيدة النواة بين الأثخاص الذين يتتاولون جرعاً زائدة من الباراسيتامول بعينة

\begin{tabular}{|c|c|c|c|c|}
\hline Sig. & $\begin{array}{c}\text { Extrem values } \\
\text { cell/mm } / \mathbf{m m}^{3}\end{array}$ & $\begin{array}{c}\text { Mean } \pm \text { S.D. } \\
\text { cell/mm } / \mathbf{m m}^{3}\end{array}$ & No.of Subject & Groups \\
\hline
\end{tabular}




\begin{tabular}{|c|c|c|c|c|}
\hline $0.000^{*}$ & $360-800$ & $634 \pm 156$ & 30 & Samples \\
\cline { 2 - 5 } & $140-500$ & $170 \pm 16$ & 30 & Control \\
\hline
\end{tabular}

(* الاختلافات عند مستوى معنوية (P

اتفقت نتائج دراستتا مـع دراسـة الباحث (Oyedeji et al., 2013) الذي تابع تأثيرات الباراسيتامول وبتركيز

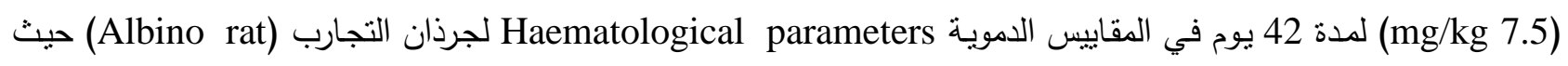

اظهرت نتائج دراسته عدم وجود فروقات معنوية في العدد الكلي لكريات الدم البيضاء في حين ظهر ارتفاع معنوي في اعداد

الخلايا العدلة والوحيدة النواة مقارنة بعينة السيطرة.

ان من اهم الاستتاجات التي نوصلنا اليها في دراستتا هي وجود اختلال في نسب الخلايا البيضاء التي تعد الخط

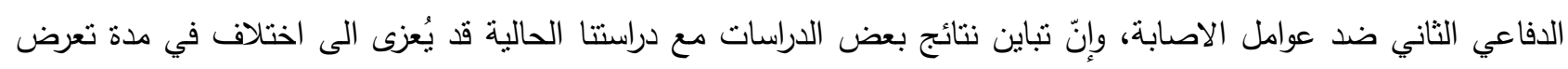

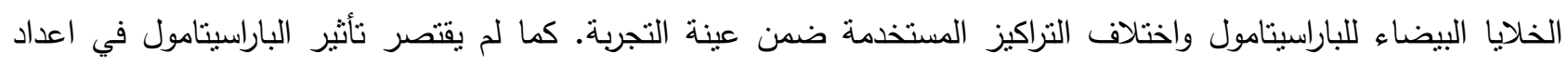

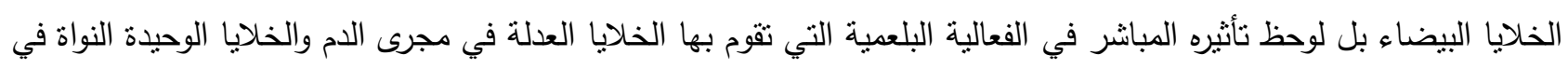

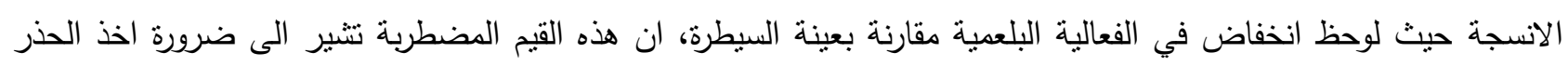

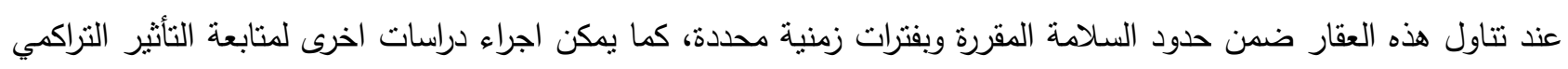
لهذا العقار في جميع الفعاليات الحيوية والانظمة الخلوية.

\section{المصادر الأجنبية}

AL-Kakey, I.S.; Al-Hussary, N.A.; Mohammed, I.H.(2006). Effect of Daonil in combination with paracetamol or oxytetracycline in cholesterol levels in blood of rats. Rafidain $J$. Sci.,17(A1),1-8.

Allaff, R.G.; AL-Shahery, M.A.(2012). Estimation of phagocytic activity in diabetic patients (Type1,2). Rafidain J. Sci. 23(4A),31-40.

Bumenreich, M.S.(1990)."Clinical Methods The History Physical and Laboratory Examination". $3^{\text {rd }}$ ed. Walker HK, Hall WD, Hurst JW.Boston, Butterworths, 153 p.

El-Benna, J.; Dang, M.P.; Gougerot pocidalo, M.A.; Elbim, C. (2005). Phagocyte NADPH oxidase multicomponent enzyme essential for host defenses. Arch immune., 53,199-206.

ELGarbulli, F.R.; Bashasha, J.A. (2008). The hazard of paracetamol addiction on cell division. J. Sci and its Appli., 2(1), 6-11.

Eneli, I.; Sadri, K.; Camargo, C.Jr.; Barr, R.G. (2005) Acetaminophen and the risk of asthma: the epidemiologic and pathophysiologic evidence. Chest., 127,604-612.

Hawkins, L.C.; Edwards, J.N.; Dargan, P.I. (2007). Impact of restricting paracetamol pack sizes on paracetamol poisoning in the United Kingdom: a review of the literature. Drug Saf., 30 (6), 465-79.

Hongslo, J.K.; Smith, C.V.; Brunborg, G. (1993). Genotoxicity of paracetamol in mice and rats. Muta., 9(2), 93-100.

Jaeschke, H.; Bajt, M.I.(2006). Intracellular signaling mechanisms of acetaminophen- induced liver cell death. Toxical Sci., 89, 31-41.

Larson, A.M.; Polson, J.; Fontana, R.J.; Davern, T.J.; Lalani, E.; Hynan, L.S.; Reisch, J.S.; Schiodd, F.V.; Ostapowicz, G.(2005). Acetaminophen-induced acute liver failure: Results of a united states multicenter, prospective study. Hepatology.,42(6),1364-1372.

Lewis, S.M.; Bain, B.S. (2001). "Dacie and Lewis Practical Haematology Harcourt Publishers Faulty" $9^{\text {th }}$ ed., $320 \mathrm{p}$. 
Mckenzie, S.B. (1996). "Textbook of Haematology". $2^{\text {nd }}$ ed., Williams and Wilkins, A Waverly company.U.S.A., pp 605-607.

Michael, S.; Gross, A.D.; Altman, R. (2007)." The Cancer Dictionary". New York. Infobase Publishing (C2007. ISBN 9780816064113.

Mitchell, J.R.; Jollow, D.J.; Potter, W.Z.; Davis, D.C.; Gillette, J.R.; Brodie, B.B.(1973). Acetaminophen-induced hepatic necrosis.I Role of drug metabolism. J. Pharmacol Exp Ther., 187.185-194.

Moller, P.; Sindet-Pedersen, S.; Petersen, C.; Juhl, G.; Dillensch-neider, A.; Skoglund, L.(2005).Onset of acetaminophen analgesia; comparsion of oral and intravenous routes after third molar surgery. Brit. J. Anesth., 94 (5),642-648.

Nabal, M.; Librada, S.; Jose, M. (2012). The role of paracetamol and nonsteroidal anti-inflammatory drugs, in addition, toWHO stepIII opioids in the control of pain in advanced cancer. Palliative Medicine., 26(4)305-312.

Ohki, S.; Ogino, N.; Yamamoto, S.; Hayaishi, O. (1979). Prostaglandin hydroperoxides, an integral part of prostaglandin endoperoxide synthetase from bovine vesicular gland microsomes. $J$. Biol. Chem., 254 (3), 829-36. PMID 104998.

Olatosin, T.M.; Chukwuemeliezedech, U.C.H.E.; Akinduko, D.S.; Bardi, J.(2007). Effects of Moringa oleifera seed oil on acetaminophen-induced oxidative stress and liver damage in Wistar albino rats. ISOR J. Pharm. and Bio. Sci., (IOSR-JPBS)., 9(2) ver I.

Oyedeji, K.O.; Ojeniran, S.S.; Bdarinwa, A.F.(2013). Effect of paracetamol (acetaminophen)on haematological and reproductive parameters in male albino rats. Inter J. Pharm Sci Review and Res., 20(2)296-300.

Scaffidi, P.; Misteli, T.; Bianch, M.E. (2002). Release of chromatin protein HMGB1 by necrotic cell triggers inflammation. Nature., 418,191-195.

Seriki, A.S; Adebayo, O.F.; Oshagbemi A.; Uche, O.(2015). Effect of paracetamol-induced liver damage on some hematological parameter; Red blood cell (RBC) count, white blood cell (WBC) count and packed cell volume (PCV) in Wistar Rats of either sex INDO American. J. Pharm Res., ISSN no:pp. 2231-6876.

Simmons, A.; Statland, B.E. (1997). "Hematology a Combined Theoretical and Technical Approach" $2^{\text {nd }}$ ed. By Butter worth, Heinemann, U.S.A., pp.407-408.

Thura, A.K. (2014). Apoptotic activity of paracetamol on normal lymphocyte by DNA fragmentation measurements. Euro J. Exper Bio., 4 (5),1-6.

Tsung, A.; Sahai, R.; Tanaka, H.; Nakao, A.; Fink, M.P.; Lotze, M.T. (2005). The nuclear factor HMGB1 mediators hepatic injury after murine liver ischemia reperfusion. J. Expermental Medicine. 201(7)1135 p.

Woolley, D.; Woolley, A.(2017). "Practical Toxicology: Evaluation, Prediction, and Risk". $3^{\text {ed }}$ ed. CRC Press. 330 p.

Yilmaz, M.Z.; Sarihasan, B.B.; Kelesaka, E.; Tas, N.; Caglartorun, A.; KoKsal, E.; Kuruoglu, E. (2015). Comparison of the analgesic effect of paracetamol and tramadol in lumbar disc surgery. Turkish J. Med. Sci.,45,438-442.

Yoon, E.; Babar, A.; Choudhary, M.; Kutner, M.; Pyrsopoulos, N. (2016). Acetaminophen-induced hepatotoxicity: a comprehensive update. J. Clin. and Trans. Hepat., 4 (2),131-42. 